\title{
əOn the Potential for Abrupt Arctic Winter Sea Ice Loss ${ }^{\mathscr{D}}$
}

\author{
S. BATHIANY \\ Department of Environmental Sciences, Wageningen University, Wageningen, Netherlands, and Max Planck \\ Institute for Meteorology, Hamburg, Germany \\ D. Notz, T. Mauritsen, G. RAedel, AND V. Brovkin \\ Max Planck Institute for Meteorology, Hamburg, Germany
}

(Manuscript received 7 July 2015, in final form 19 January 2016)

\begin{abstract}
The authors examine the transition from a seasonally ice-covered Arctic to an Arctic Ocean that is sea ice free all year round under increasing atmospheric $\mathrm{CO}_{2}$ levels. It is shown that in comprehensive climate models, such loss of Arctic winter sea ice area is faster than the preceding loss of summer sea ice area for the same rate of warming. In two of the models, several million square kilometers of winter sea ice are lost within only one decade. It is shown that neither surface albedo nor cloud feedbacks can explain the rapid winter ice loss in the climate model MPI-ESM by suppressing both feedbacks in the model. The authors argue that the large sensitivity of winter sea ice area in the models is caused by the asymmetry between melting and freezing: an ice-free summer requires the complete melt of even the thickest sea ice, which is why the perennial ice coverage decreases only gradually as more and more of the thinner ice melts away. In winter, however, sea ice areal coverage remains high as long as sea ice still forms, and then drops to zero wherever the ocean warms sufficiently to no longer form ice during winter. The loss of basinwide Arctic winter sea ice area, however, is still gradual in most models since the threshold mechanism proposed here is reversible and not associated with the existence of multiple steady states. As this occurs in every model analyzed here and is independent of any specific parameterization, it is likely to be relevant in the real world.
\end{abstract}

\section{Introduction}

The recent rapid retreat of Arctic summer sea ice has raised the question of whether global warming can bring Arctic sea ice to a so-called tipping point (Lindsay and Zhang 2005; Winton 2006; Notz 2009). This term implies that at a certain level of warming, sea ice loss would accelerate substantially in contrast to the more gradual change of the forcing. Such rapid loss could have severe consequences for the Arctic

๑ Denotes Open Access content.

Supplemental information related to this paper is available at the Journals Online website: http://dx.doi.org/10.1175/JCLI-D-150466.s1.

Corresponding author address: S. Bathiany, Department of Environmental Sciences, Wageningen University, NL-6700 AA, Wageningen, Netherlands.

E-mail: sebastian.bathiany@wur.nl climate and ecosystems. In case of large positive feedbacks, two steady climate states for the same $\mathrm{CO}_{2}$ concentration could exist and the abrupt change at a bifurcation point would be irreversible. However, simulations with complex climate models indicate that the transition to a summer without any sea ice is gradual (Wang and Overland 2012; Overland and Wang 2013) and that multiple steady states do not exist (Tietsche et al. 2011; Li et al. 2013). This fact is in agreement with a simplified column model including a wellresolved annual cycle (Eisenman and Wettlaufer 2009; Eisenman 2012).

Under further warming this column model shows an abrupt and irreversible transition from a seasonal ice cover to an ocean without any ice, a transition we refer to as winter sea ice loss. In most comprehensive climate models, however, Arctic winter sea ice area declines gradually, and in three of these models it was explicitly shown that this transition is reversible (Armour et al. 2011; Ridley et al. 2012; Li et al. 2013). It was recently also shown that the bifurcation scenario that occurs in 


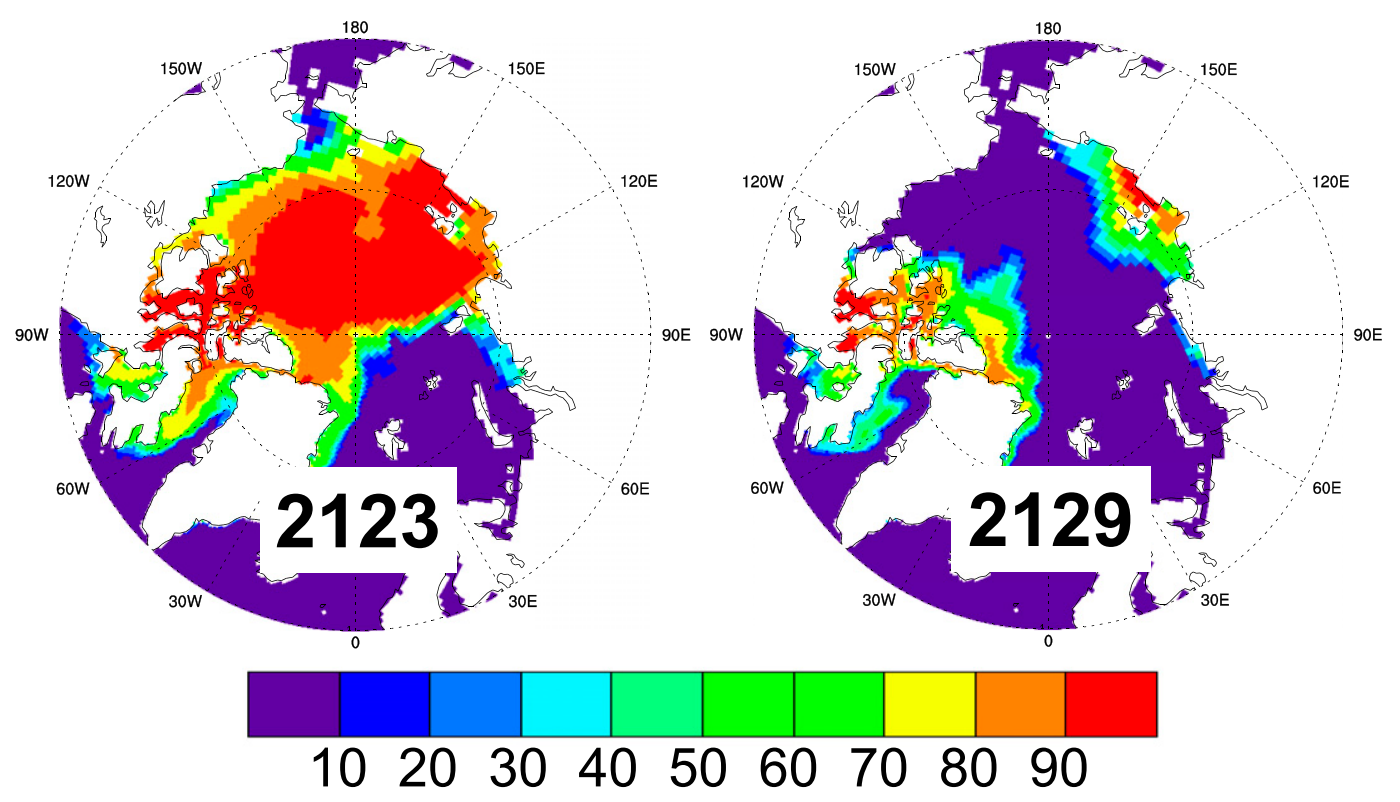

FIG. 1. MAM average of Arctic sea ice cover fraction (\%) in the years 2123 and 2129 in the RCP8.5 simulation of the MPI-ESM.

the column model is due to the lack of spatial differences and can therefore be considered as less realistic (Wagner and Eisenman 2015). Nonetheless, when analyzing seasonal differences of sea ice retreat, Eisenman et al. (2011, p. 5332) found that "[s]ome GCMs become seasonally ice free during the 1900-2100 simulation period. This leads to winter ice cover retreating faster than summer ice cover after the latter reaches zero." Moreover, abrupt Arctic winter sea ice loss was recently detected in model simulations from phase 5 of the Coupled Model Intercomparison Project (CMIP5) (Drijfhout et al. 2015). CMIP5 provides results from current comprehensive climate models and allows us to compare their response to anthropogenic forcing (Taylor et al. 2012).

The most striking winter sea ice decline occurs in the Earth system model of the Max Planck Institute for Meteorology, MPI-ESM (Giorgetta et al. 2013; Notz et al. 2013), where an ice area of several million square kilometers disappears within only a few years (Fig. 1). Winton $(2006,2008)$ showed that in the version of MPIESM that he analyzed, this transition is accompanied by an increased ice-albedo feedback, concluding that this feedback is responsible for the high rate of winter sea ice loss. The ice-albedo feedback plays a role for winter sea ice because the seasonal cycle of sea ice area lags the insolation cycle by approximately three months. Thus, ice volume and area are near their annual maximum when the sun rises in March. Li et al. (2013) further speculated that a convective cloud feedback proposed by Abbot and Tziperman (2008) could also play a role for the winter sea ice loss in MPI-ESM: In an Arctic Ocean without winter sea ice, the warmer and wetter conditions could trigger the formation of convective clouds, resulting in enhanced downwelling longwave radiation at the surface and reduced cooling to space. This warming due to the cloud radiative effect would then help to keep the Arctic ice-free.

In this study we propose a different explanation for the abrupt sea ice loss in MPI-ESM that also explains the sensitive Arctic winter sea ice area in the other models: the freezing temperature imposes a threshold for the formation of winter ice. Where the ocean no longer cools to the freezing temperature in winter, sea ice can essentially disappear from one winter to the next. If the basinwide conditions are spatially homogeneous enough, this mechanism can result in a rapid sea ice loss in a large area.

In the following, we first show that Arctic winter sea ice area is more sensitive to warming than summer sea ice area in CMIP5 models. We then outline the essence of our explanation using an idealized ice-thickness distribution (ITD) model that resolves many thickness classes in contrast to the slab model by Eisenman and Wettlaufer (2009). To show that the mechanism is indeed active in comprehensive climate models, we show consistent sea ice area and thickness changes in these models. Thereafter, we present additional simulations with MPI-ESM, showing that neither surface albedo nor radiative cloud feedbacks can explain the abrupt sea ice 
TABLE 1. CMIP5 models which were run beyond the loss of Arctic winter sea ice or until the year 2300 (for the RCP8.5 scenario). The year of winter sea ice loss marks the time when Arctic sea ice area averaged over MAM drops below 1 million $\mathrm{km}^{2}$. (Expansions of acronyms are available online at http://www ametsoc.org/PubsAcronymList.)

\begin{tabular}{lcc}
\hline \multicolumn{1}{c}{ Model } & $\begin{array}{c}\text { Final year of } \\
\text { RCP8.5 simulation }\end{array}$ & $\begin{array}{c}\text { Approximate year } \\
\text { of Arctic winter } \\
\text { sea ice loss }\end{array}$ \\
\hline MPI-ESM-LR & 2300 & 2130 \\
CSIRO Mk3.6.0 & 2300 & 2170 \\
BCC_CSM1.1 & 2300 & 2190 \\
IPSL-CM5A-LR & 2300 & 2200 \\
CCSM4 & 2300 & 2200 \\
HadGEM2-ES & 2300 & 2110 \\
CNRM-CM5 & 2300 & 2160 \\
GISS-E2-H & 2300 & - \\
GISS-E2-R & 2300 & - \\
GFDL CM3 & 2100 & 2100 \\
MIROC-ESM & 2100 & 2100 \\
MIROC-ESM-CHEM & 2100 & 2100 \\
\hline
\end{tabular}

loss in this model. Furthermore, we demonstrate with a simple box model, capturing the essence of the ice-area parameterization in MPI-ESM, that our thermodynamic argument is sufficient to explain the abrupt ice loss. We finally argue why other feedbacks are unlikely to play a dominant role also in other complex climate models and discuss important differences between the Arctic and the Southern Hemisphere.

\section{Sensitivity of Arctic sea ice to warming}

We analyze all available CMIP5 simulations where Arctic winter sea ice is lost under increasing atmospheric $\mathrm{CO}_{2}$ levels (Table 1). As a definition of ice-free conditions, we demand that less than 1 million $\mathrm{km}^{2}$ of seasonally averaged sea ice area north of $75^{\circ} \mathrm{N}$ remain at the end of the simulation. The selection of models is not sensitive to the choice of this definition. For example, applying a threshold of 2 million $\mathrm{km}^{2}$ would result in the same selection of models. The loss of Arctic sea ice during the whole year that we examine here only occurs under the large radiative forcing of the RCP8.5 simulations. In these simulations, the $\mathrm{CO}_{2}$ concentration is prescribed and shows an accelerating increase until the year 2100 (implying a radiative forcing from well-mixed greenhouse gases of $8.5 \mathrm{~W} \mathrm{~m}^{-2}$ ), followed by a stabilization period with a decelerating increase (Meinshausen et al. 2011). In the year 2250, the $\mathrm{CO}_{2}$ concentration reaches its final level of almost $2000 \mathrm{ppm}$. $\mathrm{CO}_{2}$ concentration and radiative forcing both remain constant after the year 2250. While most models were run only to the year 2100, extended simulations until 2300 were performed with nine models (Hezel et al. 2014). Of these nine models, two (GISS-E2-H and GISS-E2-R) do not show sufficient warming to produce Arctic winter sea ice loss due to their small climate sensitivity. In contrast, in three of the models only run to 2100 (GFDL CM3, MIROC-ESM, and MIROC-ESM-CHEM), winter sea ice loss occurs (Table 1). Because of the close similarity of the two versions of MIROC-ESM, we show results from MIROC-ESM but not MIROCESM-CHEM.

We refer to the transition from perennial to seasonal ice cover as the loss of summer ice. The loss of winter sea ice marks the transition from a seasonal ice cover to an ice-free ocean and occurs afterward (at higher $\mathrm{CO}_{2}$ concentration). Winter sea ice loss is thus not necessarily related to a sudden melt of a large ice amount, but occurs when the seasonal ice no longer forms in the coldest time of the year. Often, the ice-area change from year to year is fastest in March-May (MAM). We refer to sea ice in these months as winter ice and to ice in September-November (SON) as summer ice because these seasons include the annual maximum and minimum ice coverage due to the lag in the seasonal cycle compared to solar insolation.

In the following, we compare the loss of summer (perennial) sea ice with the loss of winter (seasonal) sea ice. It is important to note here that our approach differs from previous studies comparing summer and winter sea ice retreat. For example, Eisenman (2010) and Eisenman et al. (2011) compare the retreat of winter and summer sea ice area in the complete Northern Hemisphere over the same time period. For a given global mean temperature, winter sea ice extends farther south than summer sea ice, which is mostly confined to the almost land-free Arctic Ocean. In contrast, the absolute hemispheric sea ice area that can occur in winter is limited due to the large landmasses (mainly Siberia and North America). Because of this continental masking effect, it is problematic to compare sea ice areas and their trends in different seasons over the same time period (Eisenman 2010). The approach we follow in this study is to compare the decline of summer ice coverage to the decline of winter ice coverage that occurs much later (in a warmer climate), but in the same region. We focus on the Arctic Ocean $\left(75^{\circ}-90^{\circ} \mathrm{N}\right)$. Enlarging our area of analysis yields similar results because little summer sea ice exists outside the Arctic Ocean even in the present climate.

Figure 2 shows the decline of winter versus summer sea ice in state space diagrams of sea ice area versus global annual mean temperature to account for the fact that the rate of global warming changes over time in the RCP8.5 scenario. For each model, we compare the retreat between winter and summer sea ice loss for a 

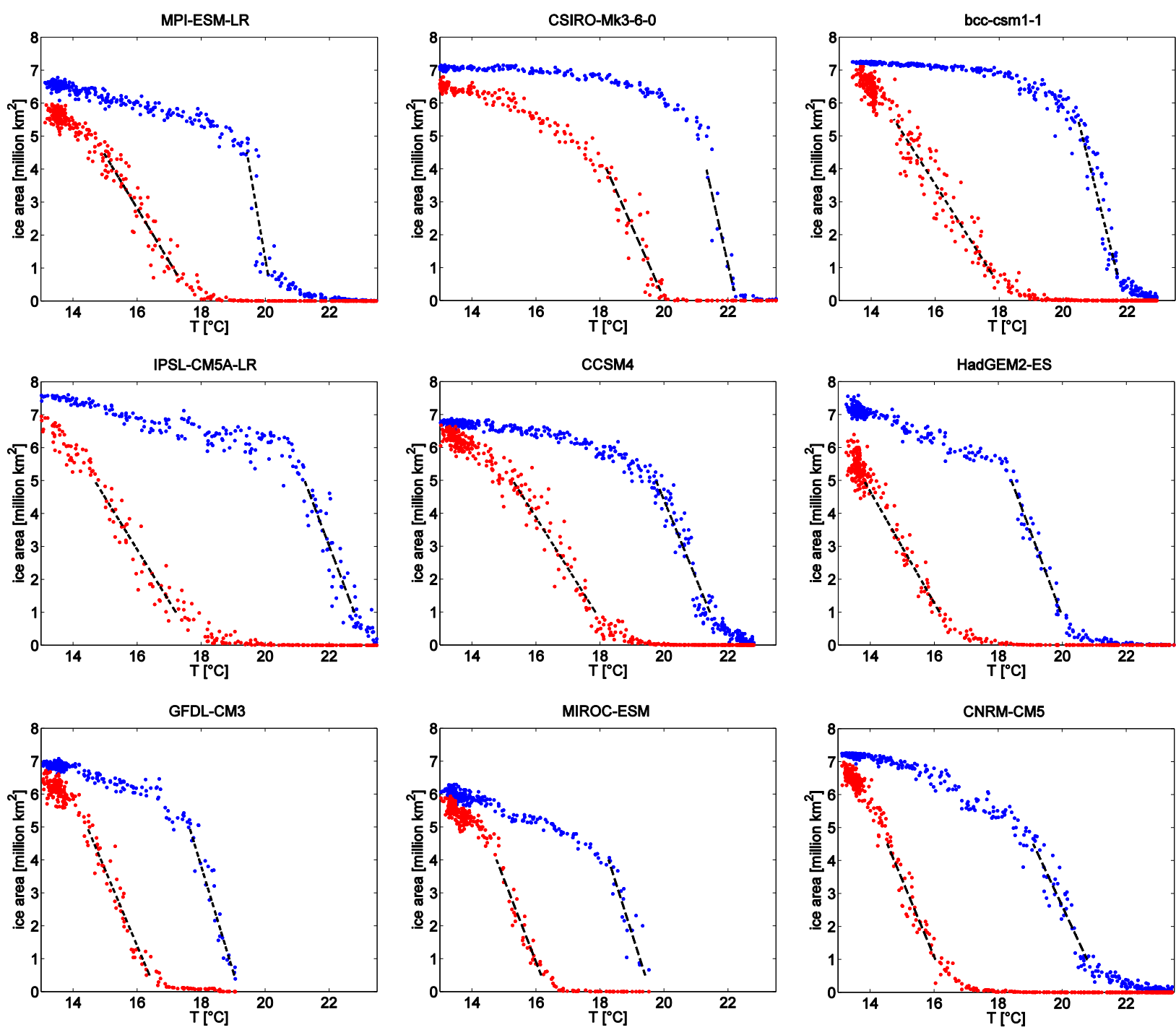

FIG. 2. Sea ice area in the Arctic $\left(75^{\circ}-90^{\circ} \mathrm{N}\right)$ vs global annual mean surface air temperature in complex climate models. Each dot represents a seasonal average over SON (red) or MAM (blue) of a particular year in the historical or RCP8.5 simulation. The dotted black lines result from a linear orthogonal regression in the ice area regime with the steepest change. Their absolute slopes are shown as sensitivities in Fig. 3a. For a given model, the ice-area range is identical for summer and winter ice loss, but differs somewhat between models to ensure that the linear approximation is reasonable in each model and season.

similar areal coverage (i.e., a given area on the $y$ axes), not for a similar climate (i.e., a given temperature on the $x$ axes). A characteristic feature of each trajectory of winter ice loss is that winter ice area is almost unaffected by warming initially, but becomes sensitive to warming at a distinct "kink" in the trajectory. This change in slope occurs because sea ice first gradually retreats in the Atlantic sector, until it also disappears in the rest of the Arctic (Fig. 1) where ocean temperatures are lower. Whereas the existence of such a kink is therefore not surprising, we are interested in the differences between the trajectories of summer and winter sea ice loss. As the land distribution is constant over time, such differences cannot be attributed to the masking effect of the continents or the choice of the region.

Two notable differences between summer and winter sea ice loss exists in the models. First, summer sea ice decline is more linear, with no or a less pronounced change in slope (Fig. 2). In a climate that is colder than the historical period, summer ice area would also be saturated due to the limited area that can be covered. However, some models show a linear decline of summer ice area, whereas in models where a kink is visible also for summer sea ice, this kink does not occur at the same ice area as the kink for winter sea ice. This points to differences in the distribution of sea ice volume during 

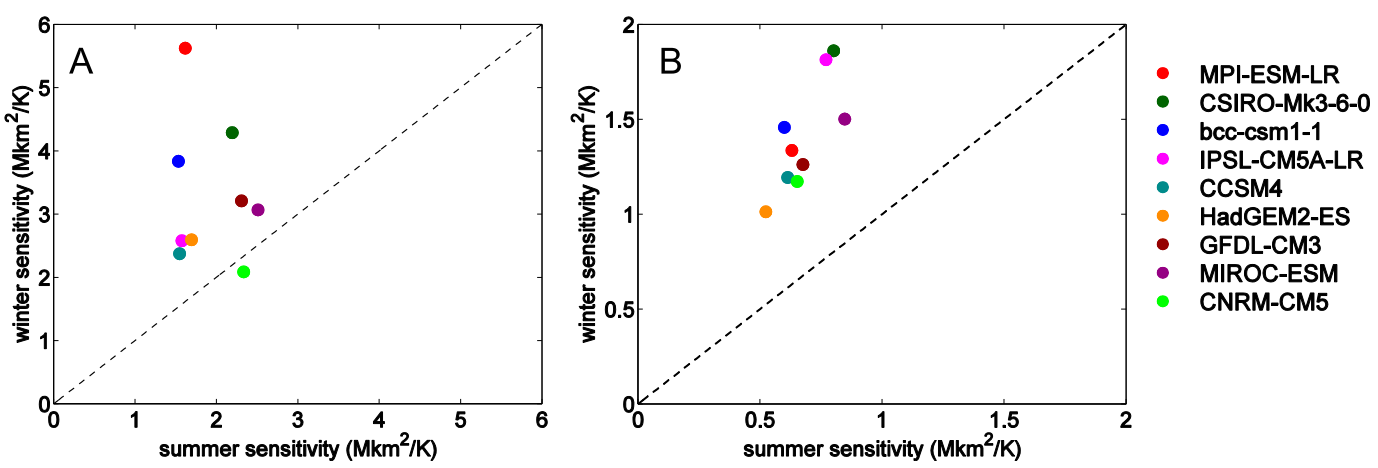

FIG. 3. (a) Sensitivity of Arctic winter (MAM) ice area vs summer (SON) ice area to global annual mean temperature change in million $\mathrm{km}^{2}$ ice-area loss per ${ }^{\circ} \mathrm{C}$ global warming in different comprehensive models. The sensitivities are obtained from an orthogonal linear regression of sea ice area vs temperature over the same range of sea ice area (Fig. 2). (b) As in (a), but for Arctic instead of global annual mean temperature change. The dashed line marks the 1:1 relation in both diagrams.

summer and winter ice loss. Second, the sensitivities of ice-area loss beyond the winter sea ice kink differ between summer and winter. We calculate these sensitivities using an orthogonal linear regression of sea ice area versus temperature in the sea ice area range with the fastest (and approximately linear) winter ice loss. For a certain model, the regression is applied over the same range of sea ice area for winter and summer (black lines in Fig. 2).

Our comparison reveals that the Arctic winter sea ice area is more sensitive to global warming than summer sea ice area in all models except the CNRM model (Fig. 3a). The low winter sensitivity in CNRM probably results from the large contribution of the ice-albedo feedback to the model's Arctic amplification (Pithan and Mauritsen 2014): After the loss of summer sea ice the Arctic annual mean warming slows down more than in other models. Consequently, when calculating the sensitivity of Arctic sea ice area to Arctic (instead of global mean) annual warming, all models display a larger winter ice sensitivity (Fig. 3b). In contrast to the asymmetry in sea ice area loss, the rate of sea ice volume loss is similar in both seasons (see Fig. S1 in the supplemental material, available online at http://dx.doi.org/ 10.1175/JCLI-D-15-0466.s1) with a tendency of an even smaller rate of winter volume loss than summer volume loss in the Pacific sector (Fig. S2) and North American sector of the Arctic Ocean (a feature we will discuss in section 5). Interestingly, the largest fraction of winter ice-area loss in the comprehensive models occurs only when ice volume is already very small, compared to the more linear area-volume relationship for summer ice. This indicates that the systematic difference between winter and summer ice-area sensitivity (Fig. 3) is hardly affected by the volume sensitivities. It also suggests that the same volume is distributed more homogeneously in winter compared to summer, a phenomenon that we explain in the following section.

\section{An idealized ice-thickness distribution model}

We now develop a conceptual ice-thickness distribution model to explain why winter sea ice area can be more sensitive to warming than summer sea ice area, given the same rate of volume loss. The model is used to conceptually explain a single thermodynamic mechanism, which is why we neglect unrelated processes in the model formulation. The model approach and notation we use are based on Thorndike et al. (1975). The model calculates a continuous evolution of an ice-thickness distribution $g(h)$ that assigns an area fraction $g(h) d h$ to each thickness interval $d h$ (Fig. 4), where $h$ is ice thickness. We assume that the evolution of $g$ is only determined by melting and freezing with rate $f=d h / d t$ and by mechanical redistribution $\Psi$

$$
\frac{d g}{d t}=-f \frac{\partial g}{\partial h}-g \frac{\partial f}{\partial h}+\Psi .
$$

For simplicity, we fit an idealized thickness growth rate $f$ to the observations in Thorndike et al. (1975) that reproduces the curves in their Fig. 5:

$$
f=\left\{\begin{array}{c}
\frac{c_{1}}{h+c_{2}}, \mid \frac{d V}{d t}>0 \\
f_{\text {melt }}, \mid \frac{d V}{d t} \leq 0
\end{array},\right.
$$

where $V$ is sea ice volume and $c_{1}$ and $c_{2}$ are tuning parameters (see Table 2 for their values and all other parameters and variables of the model). The melting rate of sea ice mainly depends on the net heat flux at the ice 


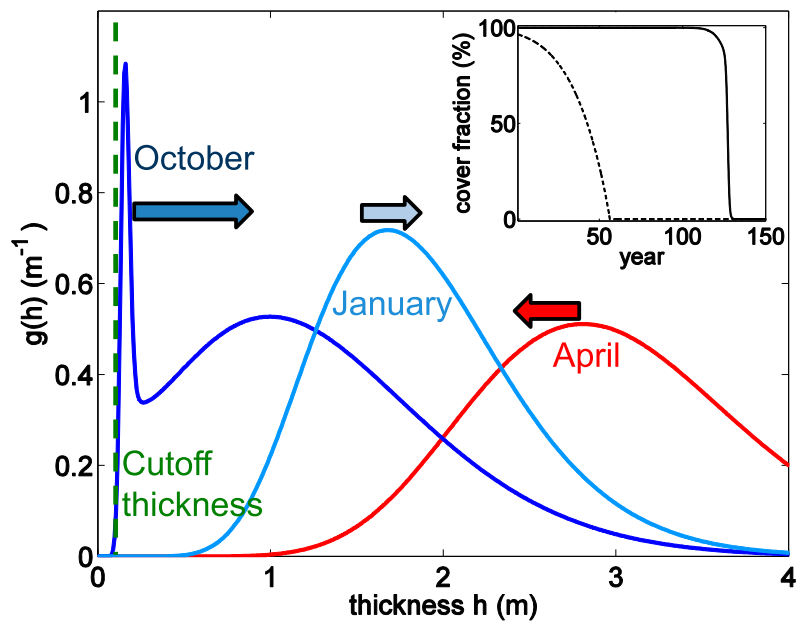

FIG. 4. Snapshot of three ice-thickness distributions (lines) and their seasonal evolution (arrows) under preindustrial conditions in the ITD model. The green vertical dashed line indicates the cutoff thickness $h_{c}$ used to diagnose the evolution of the ice-area fraction. The inset shows the evolution of the annual minimum (dashed) and maximum (continuous) of this ice-area fraction due to a volume loss that is linear in time.

surface. In the ITD model, a melting season therefore corresponds to a uniform shift of the distribution toward smaller thicknesses with constant melting rate $f_{\text {melt }}$ (red arrow in Fig. 4), producing a peak at $h=0$ (open water). During winter, the open water refreezes, shifting the peak to larger thicknesses. The fact that thin ice grows faster than thick ice (Thorndike et al. 1975) tends to sharpen the peak (blue arrows in Fig. 4).

To obtain this annual cycle of $g$, we prescribe an annual cycle of the total ice volume per unit area, $V$, in the form of a cosine. In practice, this involves two sorts of time steps: a large time step for the prescribed volume evolution, and a smaller time step to integrate Eq. (1). For each new volume, we let the thickness distribution evolve using Eq. (1) until the target volume is reached. This is evaluated by comparing the target volume to the total ice volume determined from the thickness distribution:

$$
V=\int_{0}^{\infty} g(h) h d h
$$

While for the sake of simplicity the shape of the annual cycle is imposed by our prescribed volume evolution $V(t)$, the ice thickness distributions associated with the annual volume maximum and minimum do not depend on $V(t)$, but only on its annual maximum and minimum.

Besides thermodynamic processes, the ITD is also shaped by mechanical redistribution processes (Thorndike et al. 1975; Thorndike 1992). Without such redistribution,
TABLE 2. Variables and parameters of the ice thickness distribution model.

\begin{tabular}{|c|c|c|}
\hline Property & Symbol & Values \\
\hline Thickness & $h$ & $h_{\min }-h_{\max }$ \\
\hline Minimum thickness & $h_{\min }$ & $0.0001 \mathrm{~m}$ \\
\hline Maximum thickness & $h_{\max }$ & $8 \mathrm{~m}$ \\
\hline Diagnostic cutoff thickness & $h_{c}$ & $0.1 \mathrm{~m}$ \\
\hline Number of thickness classes & $N$ & 1000 \\
\hline Thickness distribution function & $g(h)$ & Interactive \\
\hline Time & $t$ & $0-t_{\text {fin }}$ \\
\hline Total time & $t_{\text {fin }}$ & $150 \mathrm{yr}$ \\
\hline Total ice volume & $V$ & $\begin{array}{l}\text { Variable, but } \\
\text { prescribed (see text }\end{array}$ \\
\hline $\begin{array}{l}\text { Amplitude of annual } \\
\text { cycle in volume }\end{array}$ & $V_{a}$ & $1 \mathrm{~m}$ \\
\hline $\begin{array}{l}\text { Initial annual maximum } \\
\text { volume }\end{array}$ & $V_{\mathrm{ini}}$ & $2.5 \mathrm{~m}$ \\
\hline $\begin{array}{l}\text { Scale parameter of gamma } \\
\text { distribution }\end{array}$ & $\theta$ & $0.2 \mathrm{~m}$ \\
\hline Mean of gamma distribution & $k$ & $V / \theta$ \\
\hline Melting rate & $f_{\text {melt }}$ & $-0.01 \mathrm{~m} \mathrm{day}^{-1}$ \\
\hline Freezing parameter 1 & $c_{1}$ & $1 \mathrm{~m}^{2} \mathrm{day}^{-1}$ \\
\hline Freezing parameter 2 & $c_{2}$ & $0.08 \mathrm{~m}$ \\
\hline $\begin{array}{l}\text { Time since beginning of a } \\
\text { freezing season }\end{array}$ & $t_{\text {freeze }}$ & $\begin{array}{l}0-0.5 \mathrm{yr} \text { ( } 0 \text { if volume } \\
\text { is decreasing) }\end{array}$ \\
\hline Relaxation parameter & $r$ & $50 \mathrm{yr}^{-2}$ \\
\hline
\end{tabular}

the thickness-dependent growth rate would cause the ITD to converge to one single thickness. Therefore, we relax $g(h)$ toward a gamma distribution by setting

$$
\Psi=t_{\text {freeze }} r\left[h^{k-1} \frac{\exp (-h / \theta)}{\Gamma(k) \theta^{k}}-g\right],
$$

where $\Gamma$ is the gamma function, $k=V / \theta$, and $\theta, r$, and $t_{\text {freeze }}$ are fixed parameters. They are chosen in a way to obtain an ITD that is periodic in time if $V(t)$ is also periodic in time, and that is similar in shape to that observed (Bourke and Garrett 1987; Haas et al. 2008). The proportionality of $\Psi$ to the time that has elapsed since the beginning of the freezing season, $t_{\text {freeze }}$, leads to an increasing strength of the relaxation toward the end of each freezing season. This implies that mechanical redistribution is only important after the areal coverage of sea ice has grown close to $100 \%$. In reality, thin ice can be crushed and consequently piles up because of pressure from the sides, whereas divergent flow can open cracks that widen to form leads. However, we will show in section 4 that our assumption is actually justified because the ITD model can explain the Northern Hemisphere ITD in comprehensive models.

To investigate the transition to an ocean without any sea ice, we now impose a negative linear trend on the total ice volume until all ice is lost after 150 years. The trends in winter ice volume and summer ice volume are 
assumed to be identical. It is convenient to define a diagnostic cutoff thickness $h_{c}$ that demarcates between sea ice and open water in the ice-thickness distribution. The open water fraction then corresponds to the value of the cumulative distribution function $G$ evaluated at thickness $h_{c}$ :

$$
G\left(h_{c}\right)=\int_{0}^{h_{c}} g(h) d h .
$$

We choose $h_{c}=10 \mathrm{~cm}$ here, but our results are not sensitive to this particular choice. As a summer without any sea ice requires the complete melt of even the thickest sea ice, the perennial ice coverage decreases only gradually as more and more of the thinner ice melts away (dashed lines in inset of Fig. 4). As the model neglects the action of winds and waves on the newly formed ice, a uniform thin layer of ice forms each winter, with large area increases despite the small volume. This phenomenon can be observed on a lake that is suddenly covered by a thin film of ice after a cold night. As long as ice still forms in the coldest time of the year, the areal coverage remains high (i.e., the sharp peak of first-year ice in the ITD passes $h_{c}$ ). As soon as the water no longer cools to its freezing temperature during winter, this previously large area of thin ice suddenly stays open and the ice area is suddenly lost (continuous lines in inset of Fig. 4). The freezing point thus introduces a natural threshold as the nucleus of potentially abrupt change.

In a nutshell, the asymmetry between annual minimum and maximum ice-cover change arises from the fact that the distribution is broader during melting than during freezing. This has two causes: 1 ) each summer, the distribution is squeezed against the lower limit $h=$ 0 (open water formation), and 2) the thinner the ice the faster it grows. Therefore, the ice thickness remains relatively homogeneous at the beginning of the freezing season despite mechanical redistribution processes. Under a linear volume loss over time, many years are therefore needed to shift a certain area fraction to thicknesses below $h_{c}$ during summer whereas only a few years suffice to bring this fraction below $h_{c}$ in winter. As long as $h_{c}$ is small compared to the initial mean thickness, summer ice area loss is slower than winter ice area loss. The abrupt winter sea ice loss therefore results directly from the shape of the ITD.

\section{Evidence from comprehensive climate models}

The ITD model presented in the previous section has only a crude description of mechanical redistribution of sea ice, which we assumed to only play a role after winter ice has grown above the cutoff thickness. In places with large wind shear and waves, the newly formed winter sea ice could thus be deformed rapidly, which would obliterate the seasonal asymmetry in the ITD. We therefore investigate whether there is evidence for this seasonal separation in comprehensive climate models. To this end, we analyze the changes of ice coverage versus volume in the Arctic. At each individual grid cell these two quantities are a representation of the subgrid-scale ice-thickness distribution that is parameterized in the models with one to five ice-thickness classes (besides open water). In the following, we consider all grid cells in a given region at once and at all times during the historical and RCP8.5 simulations. Despite the different atmospheric and oceanic conditions between different grid cells and the differences between parameterized and resolved redistribution processes, this basinwide ice-thickness distribution (ITD*) turns out to be similar to the ITD at individual grid cells. Apparently, ITD* is dominated by the parameterization of the subgrid-scale distribution, which is the same at every grid cell.

In all models, there is a distinctive difference between March and September: given a similar ice volume, the ice areal coverage is higher in winter and much more homogeneous from one grid cell to the next compared to summer. Figure 5 shows this separation for the Pacific sector of the Arctic as an example. While winter ice cover is close to $100 \%$ already for equivalent thicknesses above $0.5 \mathrm{~m}$, the same volume is distributed less homogeneously in summer. A comparison of different areas reveals that this seasonal difference in the ITD* is a characteristic phenomenon in the Northern Hemisphere (we will discuss the situation in the Southern Hemisphere in section 6). Apparently, the mechanical breakup of newly grown winter sea ice is not strong enough to destroy the effect that the ITD model describes.

The seasonal separation tends to be clearer in models that resolve more ice-thickness classes and that have a comprehensive representation of mechanical redistribution. For example, CCSM4 (Jahn et al. 2012) and HadGEM2 (McLaren et al. 2006; Collins et al. 2011) explicitly resolve several thickness classes, while MPIESM (Notz et al. 2013), MIROC-ESM (Watanabe et al. 2011), and CSIRO (O'Farrell 1998; Uotila et al. 2013) have only two classes. However, the result of a more sensitive Arctic winter sea ice area than summer sea ice area does not directly depend on the number of thickness classes due to different parameterizations. The MPI-ESM essentially follows the parameterization of Hibler (1979) that distinguishes only between open water and ice of a single thickness. Eisenman (2007) provides an illustration of this parameterization in his Fig. 3, while the implementation in MPI-ESM is 

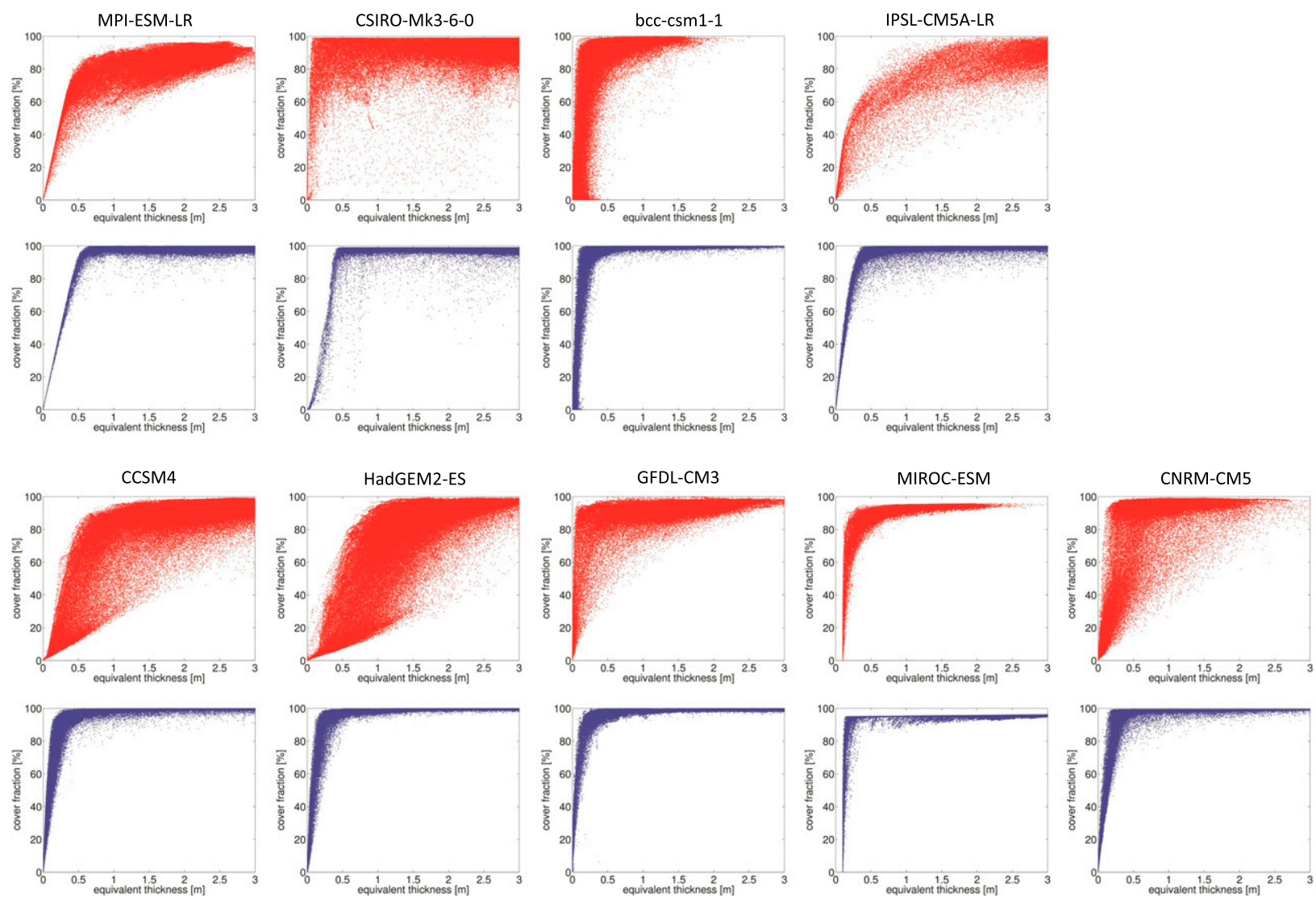

FIG. 5. Sea ice cover fraction (vertical axes) vs volume (expressed as thickness of an equivalent homogeneous volume; horizontal axes) in complex climate models. Each dot represents the September (red) or March (blue) of a particular year at a grid cell in the Pacific sector of the Arctic $\left(75^{\circ}-90^{\circ} \mathrm{N}, 120^{\circ} \mathrm{E}-120^{\circ} \mathrm{W}\right)$ in the historical or RCP8.5 simulation.

described in Notz et al. (2013). Here we briefly address the rate of change of sea ice areal coverage in a grid cell during melting and freezing within any particular year. During melting conditions, the instantaneous change of the ice-covered area fraction $A$ is proportional to the relative volume change:

$$
\frac{d A}{d t} \sim \frac{1}{V} \frac{d V}{d t}
$$

This process is slow in the present climate because most of the existing ice is too thick to be melted in one summer. During freezing conditions, the heat flux from ocean to atmosphere is largest when the existing ice is thin and when the open-water fraction is large. The ice area therefore grows exponentially when starting from open water (Hibler 1979; Notz et al. 2013):

$$
\frac{d A}{d t} \sim 1-A .
$$

Because of this fast area expansion, a short episode of cold conditions within a winter suffices to form a large sea ice area. This ice does not return the following year if the water does not cool to the freezing temperature. In contrast, if summer sea ice covers a similar area, it cannot melt within one season because its large volume limits the melting rate [Eq. (6)]. As a consequence, the parameterization captures our argument why summer and winter sea ice have different sensitivities to $\mathrm{CO}_{2-}$ induced warming over many years.

The evolution of ice volume and ice cover during a year is also consistent with this mechanism in all other Earth system models: In winter, the ice area expands from zero to close to above $80 \%$ despite relatively small volume changes compared to the melting season, when ice volume is reduced substantially before large area changes can occur (Fig. 6). In contrast to the ITD model in the previous section, the annual cycle of ice volume is not sinusoidal in the comprehensive models. Instead, the period of volume growth is longer than the period of volume loss, as can also be seen in Fig. 6. This is probably due to the asymmetric annual cycle of solar insolation at the surface, showing a large peak in early summer and constant values close to zero during Arctic winter. 

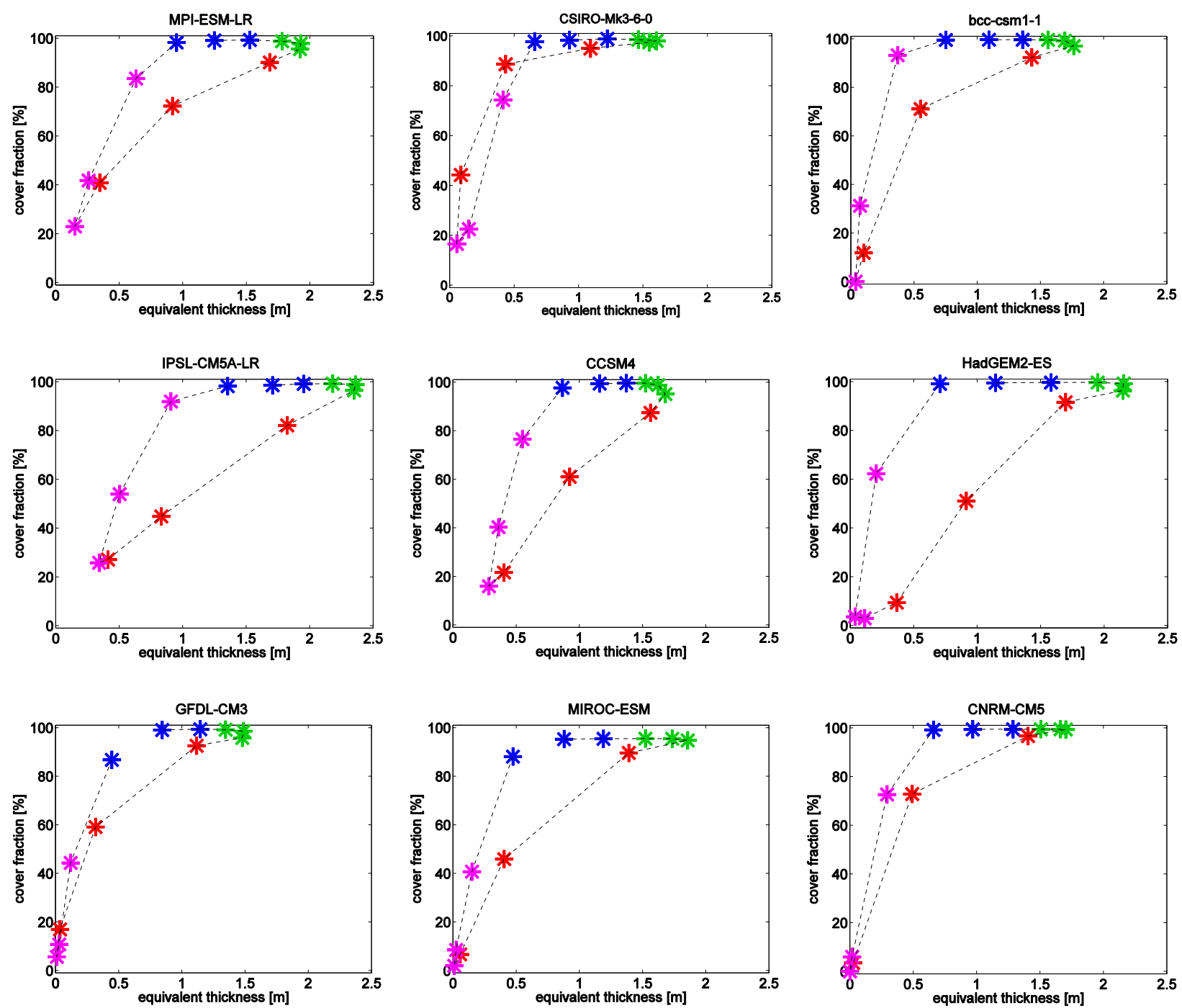

FIG. 6. Typical annual cycle of sea ice cover fraction (vertical axis) vs volume (expressed as thickness of an equivalent homogeneous volume; horizontal axis) in complex climate models. Each star marks a particular month in the RCP8.5 simulation, but averaged over the years 2080-90 for CSIRO and 2020-30 for all other models to account for the large initial ice volume in CSIRO. June-August (red), SON (magenta), December-February (blue), MAM (green). The data are taken from one single grid cell at approximately $75^{\circ} \mathrm{N}, 180^{\circ}$.

Despite this asymmetry in the annual cycle of ice volume, the annual cycle of ice area is close to sinusoidal due to the seasonal differences in the ITD.

In our explanation we have neglected weather-induced variability and the spatial heterogeneity of the conditions external to sea ice, most importantly the temperature of atmosphere and ocean. In reality, the Arctic sea surface temperature differs between locations. Consequently, when the Arctic gradually warms, the year in which the ocean does not refreeze anymore in winter will also differ between locations. The largescale loss of winter ice cover would therefore not be as abrupt as in the ITD model. However, the Arctic Ocean's temperature is sufficiently uniform in the models to maintain a large winter ice coverage at most places until summer ice loss has occurred.

The geographic distribution of Arctic sea ice documents this uniformity (Fig. 7). Under present-day conditions, the equivalent sea ice thickness is relatively heterogeneous in the models in all seasons. Under global warming, summer sea ice first disappears at the ice edge where thickness is small, so that the sea ice extent gradually decreases until even the thickest ice in the center has disappeared. In contrast, winter sea ice thickness becomes more uniform over time with little area change so that the same volume covers a larger area than in summer. The systematic differences in the geographic volume distribution between summer and 

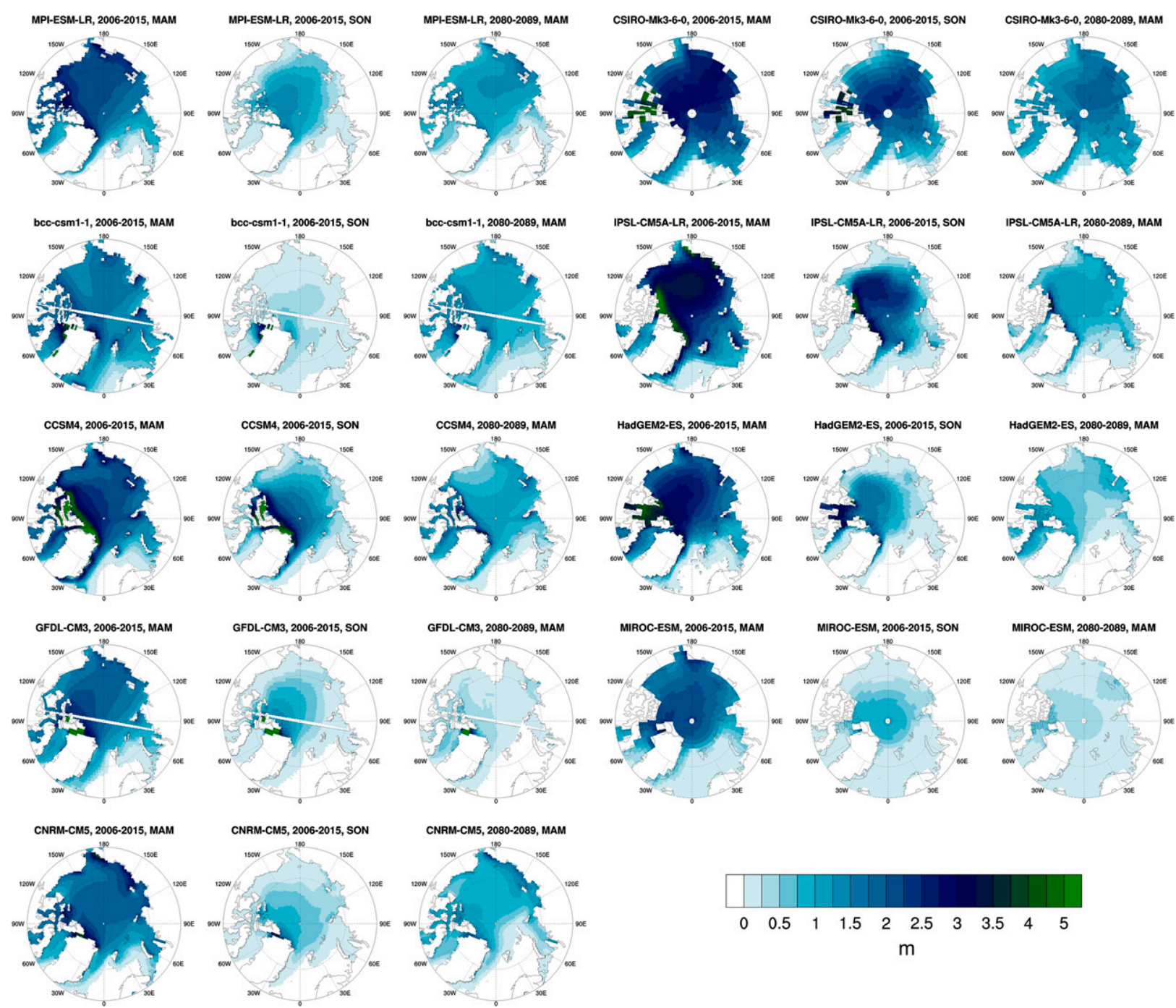

FIG. 7. Equivalent thickness $(\mathrm{m})$ of sea ice volume in the RCP8.5 simulation of all nine models analyzed in this study. For each model, MAM and SON conditions averaged over the years 2006-15 and MAM averaged over the years 2080-89 are shown.

winter are visible not only in the models with total winter sea ice loss that we analyze here (Fig. 7), but also in other CMIP5 models (Fig. S3). We therefore suspect that the other models would also display a larger sensitivity of winter ice area if they were run to larger warming.

After the winter sea ice has become thin and more homogenous, the loss of winter sea ice cover at individual grid cells occurs rapidly where the thickness falls below $0.4-0.5 \mathrm{~m}$. The precise threshold depends on what thickness is attributed to newly formed sea ice in the models' parameterizations and can be seen in Fig. 5 in form of the kink in the envelope of blue points. The icecover loss occurs with sufficient synchronicity to distinguish it from the preceding summer ice loss. Figure 8 documents this for the Pacific sector of the Arctic Ocean:
Winter ice cover stays close to $100 \%$ until just before it disappears at most grid cells while summer ice loss is more gradual. Also, a sharp threshold for the last winter sea ice is visible when the freezing temperature is exceeded at all grid cells. The cover fraction of summer and winter ice differs between grid cells, leading to the spread of cover fractions in each season for a given global mean temperature. This spread is much smaller for winter sea ice (blue) than summer sea ice (red) and ice coverage stays high at almost all grid cells until the total loss of summer ice. Thereafter, the coverage of more and more grid cells drops to zero with further global warming. Nonetheless, the spatial heterogeneity of temperature that causes this asynchronous loss is so small that winter and summer ice loss are well separated in time. 

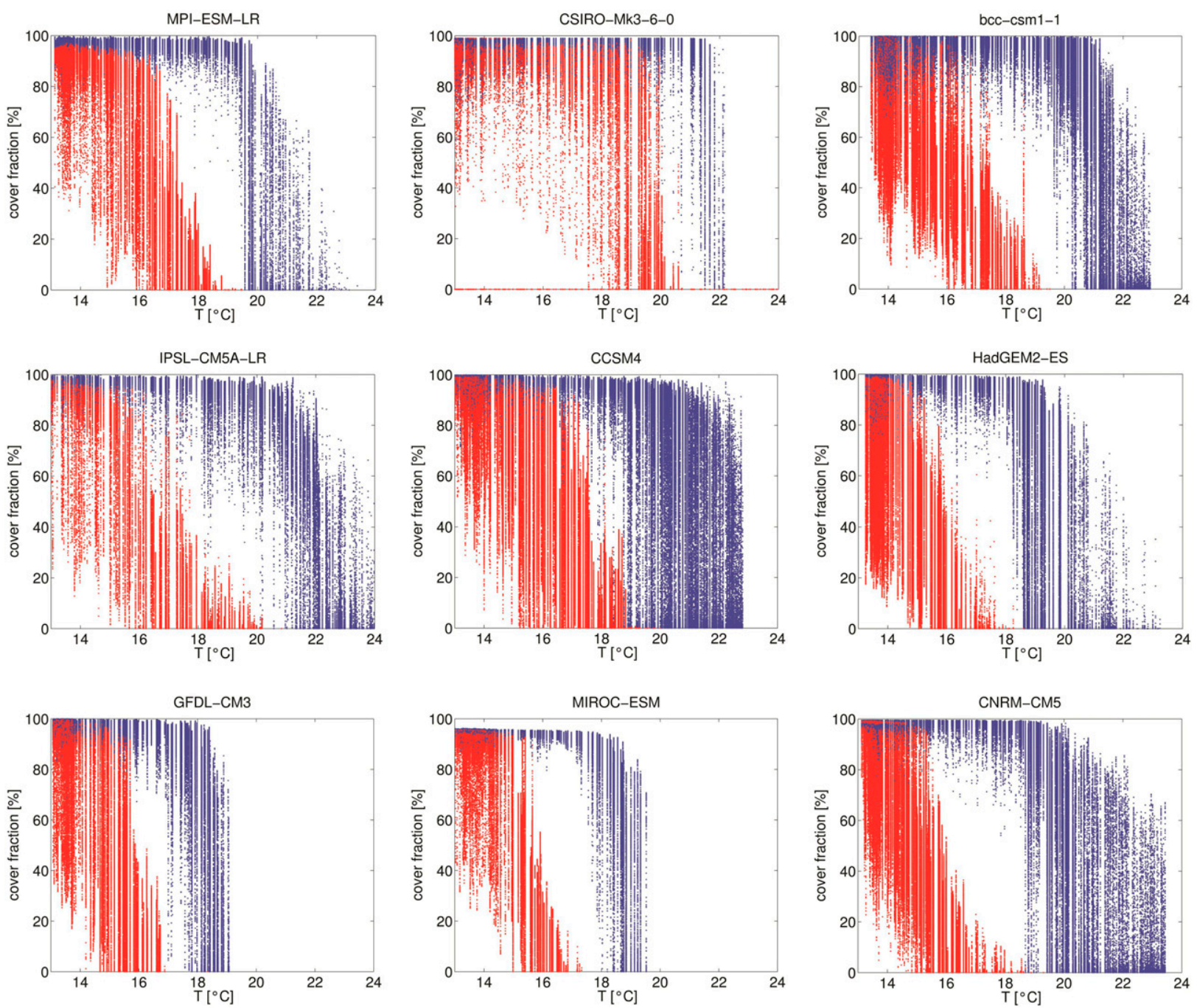

FIG. 8. Sea ice cover fraction at individual grid cells in the Pacific sector of the Arctic $\left(75^{\circ}-90^{\circ} \mathrm{N}, 120^{\circ} \mathrm{E}-120^{\circ} \mathrm{W}\right)$ vs global annual mean surface air temperature in complex climate models. Each dot represents a seasonal average over SON (red) or MAM (blue) of a particular year at one grid cell in the historical or RCP8.5 simulation.

This separation would break down if we considered the complete Northern Hemisphere as in previous studies (Eisenman 2010; Eisenman et al. 2011). On a complete hemisphere, winter sea ice disappears in some places while summer sea ice is still present in colder places at the same time. Consequently, our results do not necessarily imply that the latitude of the sea ice edge on the Northern Hemisphere has to shift with a different rate in winter and summer in the current climate. In fact, Eisenman (2010) found no seasonal differences in the rate of retreat of this ice-edge latitude in observations. When accounting for the masking effect of continents, Eisenman et al. (2011) show that in both hemispheres, winter sea ice extent decreases faster than summer sea ice extent over the same time period, but this result is influenced by the shape of Earth's surface as the area of a spherical cap is not proportional to the ice-edge latitude.

\section{The role of radiative feedbacks}

So far, we have shown that the threshold mechanism is active in all models and that it can explain why Arctic sea ice area loss is faster in winter than in summer for the same rate of warming. Radiative feedbacks are not required for this explanation. The model where this could be most questionable is MPI-ESM, because of two reasons. The first reason is an abrupt ice-area loss occurs that is associated with a distinct volume jump. The abrupt loss of volume could indicate a bifurcation that can only be introduced by feedbacks, similar to the model by Eisenman and Wettlaufer (2009). Second, 
previous studies suggested that the ice-albedo feedback (Winton 2006, 2008) or the convective cloud feedback (Abbot and Tziperman 2008; Li et al. 2013) may be responsible for the rapid loss of Arctic winter sea ice in MPI-ESM. We therefore performed two experiments where either the surface albedo or the cloud feedback is globally switched, off one at a time (Mauritsen et al. 2013), and one reference experiment where both feedbacks are active. In each experiment, atmospheric $\mathrm{CO}_{2}$ increases by $1 \%$ per year while all other external conditions are the same and constant in time. The first 140 years of the reference experiment are identical to the CMIP5 simulation 1pctCO2, which has been prolonged beyond the loss of Arctic winter sea ice to a total length of 210 years. Each experiment starts from its own preindustrial steady state to which it was spun up for the different setups. The preindustrial state that corresponds to the reference simulation is the CMIP5 simulation piControl. The three preindustrial climates are, however, fairly similar compared to the forced changes we study.

In the experiment without cloud feedbacks, the cloud liquid, ice, and cover fraction used in the atmospheric radiation calculations are prescribed to preindustrial conditions. Therefore, the cloud properties are stored for each radiation time step in an initial 50-yr simulation. In the climate change experiment (and its preindustrial control state), these quantities are read into the radiation module for a random year, but the day within the year and the time of day are the same. It should be noted that the hydrological cycle is closed and the model still forms clouds that interact with atmospheric dynamics through release of latent heat. In the experiment without ice-albedo feedback all surface properties contributing to surface albedo are prescribed from a preindustrial simulation and repeat every 30 years. With surface albedo we refer to the albedo of Earth's surface, not the albedo of sea ice alone. In both kinds of simulations, the distributions of clouds and surface albedo are prescribed globally, not only in the Arctic.

Because of the impact of feedbacks on climate sensitivity, the sudden sea ice loss occurs at different times in the experiments. However, the relationship between sea ice area and global mean temperature does not qualitatively change in any of the three experiments (Fig. 9a). On the contrary, the difference between summer and winter sensitivity even increases when surface albedo feedbacks are disabled: while the loss of summer sea ice occurs more gradually, disabling the albedo feedback just delays the loss of the winter ice cover until global mean temperature has risen by another $2 \mathrm{~K}$. Arctic winter sea ice area stays high while the whole Arctic basin is cold enough, but the sensitivity below
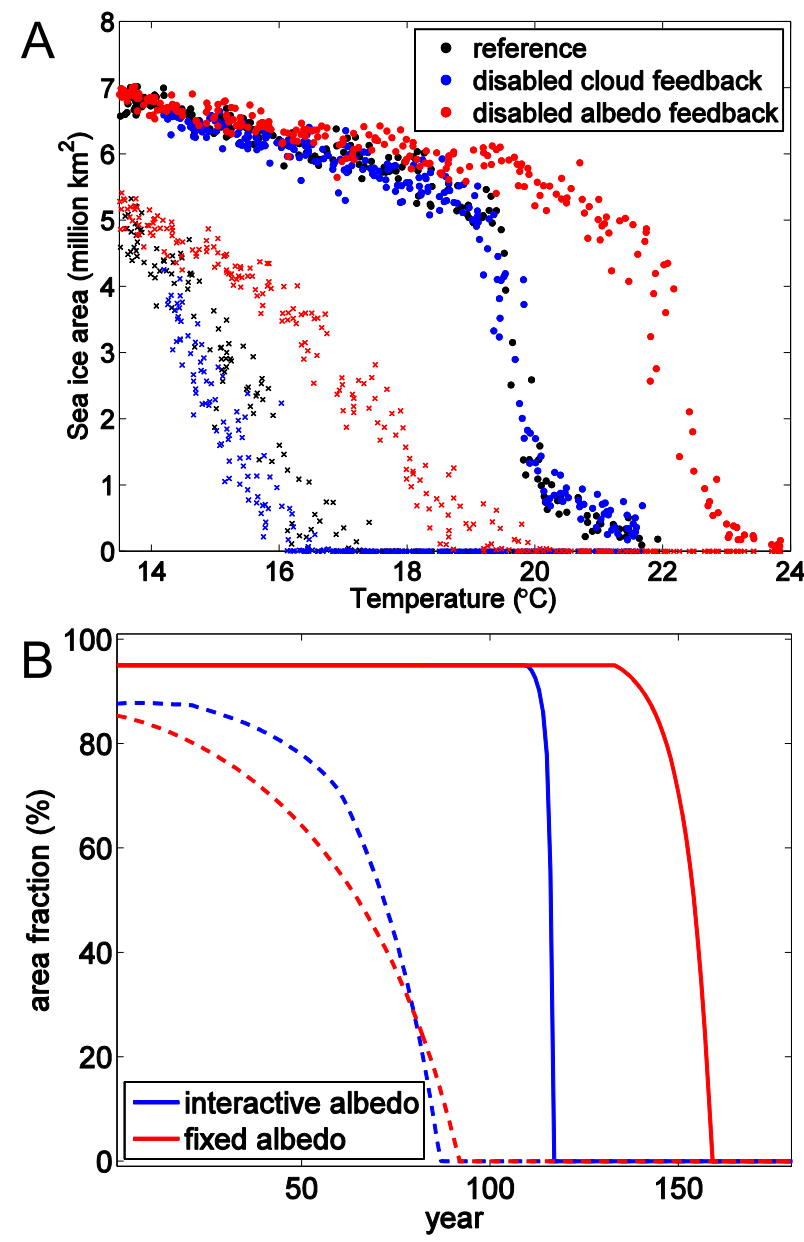

FIG. 9. (a) Arctic $\left(75^{\circ}-90^{\circ} \mathrm{N}\right)$ sea ice area in March (dots) and September (crosses) vs global annual mean surface air temperature in three experiments with the MPI Earth system model. (b) Evolution of sea ice area fraction in the box model of Eisenman (2007). Dashed lines mark the annual minimum, continuous lines the annual maximum. Both models are forced with a $1 \% \mathrm{CO}_{2}$ increase per year.

5 million $\mathrm{km}^{2}$ looks comparable to the two other simulations. Therefore, neither the ice-albedo feedback nor the cloud feedback is required to explain the abrupt Arctic winter sea ice loss in MPI-ESM.

The low importance of these feedbacks is also indicated by time series of atmospheric variables in our simulations (Fig. S4). If a positive feedback was the reason for the sudden ice loss, one would expect a synchronized abrupt change of the variables involved in the feedback. Although a sudden increase of convective precipitation does occur, we observe no pronounced jump in the time series of cloud cover, vertically integrated water vapor, liquid water, and ice during any season. Also, the cloud feedback would be most effective in the dark period of the year. However, in MPI-ESM the sea ice cover decreases gradually between 
December and late February and only shows an abrupt change after sunrise. The shortwave and longwave cloud radiative effect and the downwelling longwave radiation increase abruptly between March and May. This occurs not only in the reference simulation but also in the experiment without cloud feedbacks, and must therefore be due to the masking effect of clouds (Soden et al. 2008). At the same time, absorbed shortwave radiation at the surface increases by $20 \mathrm{~W} \mathrm{~m}^{-2}$, approximately twice as much as the increase in downwelling longwave radiation. The surface albedo feedback therefore appears to be more important than the cloud feedback and may affect the seasonal timing of the abrupt change.

To demonstrate that no other feedback is necessary to explain the abrupt winter sea ice loss, we now analyze the model's sea ice area evolution in an idealized form: Eisenman's 2007 model (Eisenman 2007). The model solves the energy balance for a slab of ice in a mixedlayer ocean and includes a continuous annual cycle. The $\mathrm{CO}_{2}$ concentration and the fluxes of incoming solar radiation and lateral heat fluxes in atmosphere and ocean are prescribed. The energy budget at each time step then yields the temperature changes in ice and water as well as the ice-volume change. The area fraction of ice cover is calculated using Hibler's approach (Hibler 1979) like in MPI-ESM. In the original Eisenman model, $\mathrm{CO}_{2}$ has to be increased roughly by a factor of 20 to melt the ice because, by design, positive feedbacks other than the ice-albedo feedback are missing. We have therefore added an additional flux of $20 \mathrm{~W} \mathrm{~m}^{-2}$ per $\mathrm{CO}_{2}$ doubling to the downwelling longwave radiation at the surface [Eq. (30) in Eisenman (2007)] to match the sensitivity of MPI-ESM. While the additional term makes the model more sensitive to $\mathrm{CO}_{2}$, it does not change its behavior: When forced with an annual $1 \%$ increase in $\mathrm{CO}_{2}$, the annual minimum of the area fraction decreases gradually, whereas the annual maximum shows an abrupt decline (Fig. 9b). As in MPI-ESM, this transition is somewhat less abrupt but still much faster than the summer ice retreat when a preindustrial surface albedo is prescribed independently of the ice cover (i.e., when the ice-albedo feedback is switched off). As the model by Eisenman (2007) is not a global climate model, Fig. 9b shows sea ice area fraction versus time while Fig. 9a shows sea ice area versus global mean temperature. Nonetheless, these figures are directly comparable due to the choice of the scenario: as the radiative forcing depends logarithmically on the $\mathrm{CO}_{2}$ concentration, which increases exponentially, global mean temperature increases linearly over time in the $1 \% \mathrm{CO} 2$ scenario. It should also be noted that even when the ice-albedo feedback is included, multiple equilibria occur in only a small parameter range and are not a robust emergent property of Eisenman's model. As no other positive feedbacks are included in the box model, it corroborates the view of a threshold-induced, rather than a feedbackdriven, rapid change.

Interestingly, the evolution of sea ice volume is also similar in MPI-ESM and Eisenman's column model, with winter volume decreasing more slowly while the area fraction is still large, and declining rapidly to zero thereafter (Fig. S5). This behavior is due to the large growth rate of thin ice. As most of the ice can form rapidly in the beginning of each winter, the shortening of the period with temperatures below the freezing point leads to little change in total ice volume from one winter to the next. This could explain the smaller loss rate of winter volume compared to summer volume in the open ocean also in other models (Fig. S2). The final period of rapid volume loss in MPI-ESM and the column model occurs when sea ice no longer forms, switching from a short period with very thin (fast growing) ice to no ice. This feature does not occur in models with a better resolved ice-thickness distribution, a fact that we come back to in the following section.

\section{Discussion}

Our analysis so far has only been based on models. Unfortunately, most Earth system models simulate the present-day distribution of sea ice volume rather poorly (Holland et al. 2010; Stroeve et al. 2014). Observations show that sea ice is thickest north of the Canadian Arctic Archipelago where it is pushed against the continents by the wind, while it is much thinner in the Eurasian sector (Bourke and Garrett 1987; Laxon et al. 2013). Because of large biases in the atmospheric circulation, most models show a too homogeneous geographical distribution, or a thickness maximum at the wrong location (Bitz et al. 2002; Kwok 2011; Stroeve et al. 2014). As the basinwide distribution of thickness determines how fast and synchronized ice-area losses can occur, two questions arise:

1) How realistic is the result that Arctic winter sea ice area is more sensitive than summer ice area?

2) How fast can the loss of winter sea ice area realistically be in absolute terms?

Concerning the first question, it is remarkable that all models we analyzed show a seasonal asymmetry of Arctic sea ice loss (Fig. 3), more homogeneous winter ice (Figs. 7 and 8), and a characteristic ITD* (Fig. 5), no matter how realistically the geographical volume distribution is captured. For example, CCSM4 shows a relatively realistic volume distribution, while $\mathrm{BCC}_{-}$ CSM1.1 shows an unrealistic distribution (Stroeve 
et al. 2014). Nonetheless, both models show a similar seasonal asymmetry of ice-area retreat. Moreover, sea ice volume is distributed more homogeneously in winter than in summer also in models without winter sea ice loss (Fig. S3). We therefore conclude that the higher winter than summer sensitivity is not the result of a biased model selection. The fact that all models show a similar seasonal asymmetry, and that we can explain it conceptually, implies that the threshold mechanism is also relevant in reality. Nonetheless, it is still possible that processes that are missing in the models may also become relevant on the way to an ice-free Arctic. For example, the fact that there are more storms in winter than in summer and that much larger waves can form once summer ice is lost (Thomson and Rogers 2014) may reduce the asymmetry of winter and summer sea ice loss.

An answer to the second question is more difficult because it requires a realistic representation of the sea ice volume distribution within the Arctic basin. Unfortunately, most models fail to capture the observed spatial distribution of ice thickness (Stroeve et al. 2014). Moreover, it is possible that the parameterizations of the ITD in general and mechanical redistribution of sea ice in particular may yield unrealistic results in a climate that is much warmer than today. It is striking that the winter ice-area loss in the MPI-ESM and CSIRO model occurs much faster than in the other models. The abrupt ice-area loss in these two models is associated with an accelerated decline in ice volume (Figs. S1 and S2). The volume discontinuity in MPI-ESM can be explained by the fact that all newly formed sea ice is immediately redistributed to a predefined thickness. At the beginning of each freezing season this leads to an initially large open water fraction and a buildup of a large ice volume due to the efficient cooling. This may make the ice less sensitive to natural variability, which can cause an early melting and mechanical breakup of newly formed ice, thus enhancing the large ice-area coverage just before its complete loss. This effect also occurs in the box model by Eisenman (2007) presented in section 5. We therefore suspect that the speed of Arctic winter sea ice loss in MPI-ESM and CSIRO may be amplified by their oversimplified ice-area parameterization (Notz et al. 2013; Gordon et al. 2010; Uotila et al. 2013). A model like CCSM4 with its more sophisticated subgrid-scale ice thickness distribution and its more realistic geographical volume distribution probably provides a better assessment of the absolute loss rate of Arctic sea ice area.

Interestingly, no abrupt change occurs in the Southern Hemisphere in any model. In contrast, MPI-ESM and CSIRO show an abrupt ice-area loss in the Arctic. It is therefore instructive to focus on these two models to understand the differences between sea ice retreat in the
Arctic and the Southern Ocean. As the description of sea ice processes is identical in both hemispheres, we argue that there are fundamental geographical differences: the Arctic can be idealized as a closed ocean basin with a relatively uniform temperature due to its position around the pole. Therefore, the sea ice we see in summer and winter in our analysis has been formed in situ and mainly remains in the Arctic over the annual cycle. Accordingly, seasonal differences are more important than spatial differences in the Arctic, and a column model such as the model by Eisenman (2007) or our ITD conceptual model is appropriate to describe the evolution of ice area in this region. In contrast, sea ice in the Southern Hemisphere is formed near the coast due to the very cold winds from the Antarctic continent and is then exported toward the open ocean where it gradually melts (Fichefet and Morales Maqueda 1997; Ogura et al. 2004). This occurs in summer and winter, with a much larger sea ice extent in winter than summer. Whereas in the Arctic a large winter sea ice area can suddenly be lost when sea ice does not form anymore, the warming in the Southern Ocean only speeds up the melting process of the exported sea ice, a much more gradual process.

Two lines of evidence provide support for this hypothesis. First, the ITD* of sea ice in the Southern Ocean is much less separated between the seasons than in the Northern Hemisphere (Fig. S7). This indicates that growth and melting of sea ice are seasonally not well separated in the Southern Ocean. In contrast, the mere fact that there is mechanical redistribution and ice export is probably not a sufficient explanation, since we obtain much clearer seasonal ITD* differences in the Northern Hemisphere also in regions with substantial ice advection (e.g., east of Greenland) or temperature gradients (e.g., the North Atlantic and North Pacific). Second, large temperature gradients exist in the Southern Ocean in winter between the locations of sea ice formation near the coast and the locations of sea ice melt in the open ocean. This temperature pattern is not a mere cause of the distribution of sea ice because it persists after the ice loss (Fig. 10). It is striking that despite the very similar ITD* for winter and summer sea ice in at least some models, the models show a larger sensitivity of Southern Hemisphere winter sea ice area than summer sea ice area (Fig. S7). In contrast to the Arctic, however, this is also true for sea ice volume (Fig. S8), which indicates that the mechanisms differ between the hemispheres. It therefore remains an open question why winter sea ice loss is faster than summer sea ice loss in the Southern Hemisphere.

As we could only separate the radiative feedbacks in one single model, we also have to leave it to future studies to further investigate the importance of these 


\section{MPI-ESM-LR}
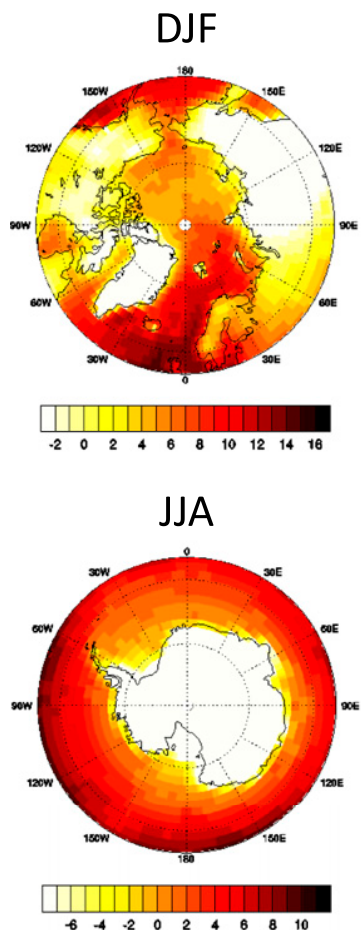
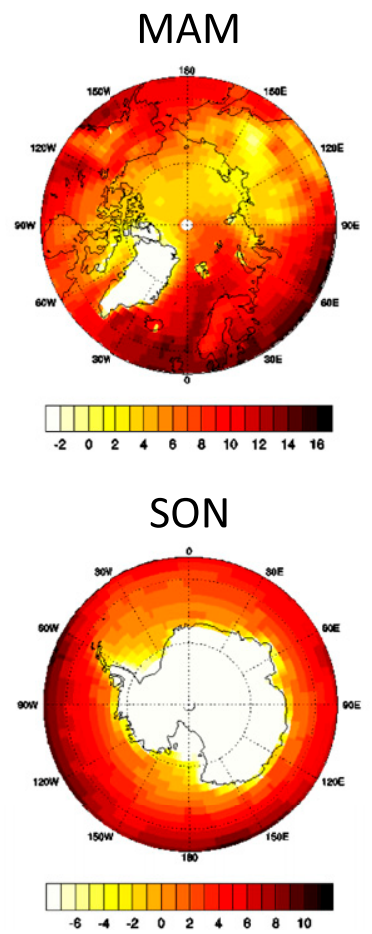

CSIRO-Mk3-6-0
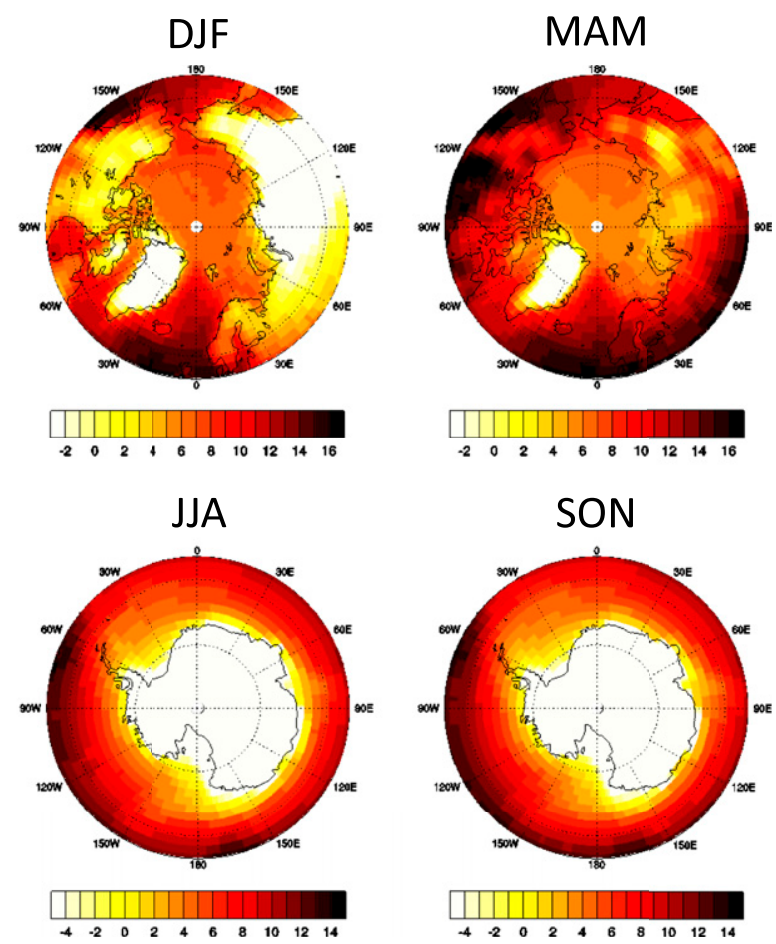

FIG. 10. Seasonal mean surface air temperature $\left({ }^{\circ} \mathrm{C}\right)$ in two models that show abrupt winter sea ice loss in the Arctic but not in the Southern Ocean. All maps show averages over the years 2271-2300 in the RCP8.5 scenario, when almost no sea ice is left.

feedbacks for Arctic sea ice loss in different models. However, the fact that the ice-thickness distribution in all models is consistent with our explanation suggests that albedo and cloud feedbacks play a minor role for Arctic winter sea ice loss not only in MPI-ESM, but also in the other models. Moreover, while the ice-albedo feedback is only active during polar day, the convective cloud feedback is most effective during polar night when it is not counteracted by the cooling shortwave effect of increased cloud cover. If either surface albedo or longwave cloud feedbacks were the main reason for rapid ice loss, the fastest change would preferentially occur either in polar day or polar night, respectively. However, rapid ice-area loss can occur before as well as after springtime sunrise (Fig. S9). Moreover, any variables involved in a strong positive feedback loop can be expected to show synchronized shifts. The absence of large shifts in cloud properties or sea ice volume during the ice-area loss therefore points to the threshold mechanism, rather than radiative feedbacks.

\section{Conclusions}

We have found that in complex climate models the transition from a seasonally ice-covered Arctic to an ocean without any sea ice year-round occurs faster than the loss of summer sea ice under the same rate of warming. We attribute this effect to the seasonal asymmetry in the ice-thickness distribution. Whereas summer sea ice is too heterogeneous for large-scale rapid shifts in sea ice area to occur over a few years, Arctic winter sea ice is spread out more homogeneously. As long as the winters are cold enough, a thin and relatively homogeneous ice cover still forms each year. Once the water does not cool to the freezing temperature anymore in winter, the small loss of ice volume from one winter to the next is associated with a large ice-area loss. This explanation allows the possibility of abrupt change although it does not rely on any positive feedback because the freezing point constitutes a natural threshold.

Regarding the generality of this threshold mechanism, the loss of Arctic summer sea ice in the near future could provide an observational lower limit for the rate of Arctic winter sea ice loss, provided that global warming will continue with a similar rate. Because of the inherent uncertainties in the models, it is difficult to provide a quantitative estimate for the sensitivity of Arctic winter sea ice area. It is plausible that the models with the most sophisticated ice-thickness distribution yield the best estimate of the sensitivity of Arctic winter sea ice area, 
which is roughly $50 \%$ larger than the sensitivity of summer ice area (Fig. 3). We consider the distinctly abrupt Arctic winter ice loss in MPI-ESM and CSIRO to be less realistic due to their simple description of the subgrid-scale thickness distribution.

Moreover, the threshold mechanism is reversible, in agreement with hysteresis experiments with the comprehensive models MPI-ESM ( $\mathrm{Li}$ et al. 2013), CCSM3 (Armour et al. 2011), and HadCM3 (Ridley et al. 2012), and in contrast to the catastrophic winter sea ice loss in the column model by Eisenman and Wettlaufer (2009). However, the large sensitivity of the sea ice area can still lead to episodes of abrupt change caused by climate forcing and natural variability (Holland et al. 2006; Drijfhout et al. 2015), implying rapid shifts also for other elements of the Arctic climate and biogeochemistry. For the radiation balance and the momentum, moisture and gas exchange, it makes a huge difference whether some thin ice or no ice at all is present. Although albedo and cloud feedbacks are not necessary for the occurrence of abrupt sea ice loss, they can amplify the resulting climate change. The generality of the threshold mechanism we have described suggests that such rapid shifts may have occurred in past climates or could occur in the future.

Acknowledgments. We acknowledge financial support by the European Commission's 7th Framework Programme under Grant Agreement 282672 (EMBRACE project). GR acknowledges support from the Federal Ministry for Education and Research in Germany (BMBF) through the research program "MiKlip" (FKZ:01LP1128B). We also acknowledge the World Climate Research Programme's Working Group on Coupled Modeling, which is responsible for CMIP, and we thank the climate modeling groups for producing and making available their model output. Computational resources were made available by the German Climate Computing Center (DKRZ) through support from the German Federal Ministry of Education and Research (BMBF). We thank Steffen Tietsche, Chao Li, Benjamin Moebis, Felix Pithan, Jochem Marotzke, Helge Goessling, Tido Semmler, and Martin Losch for the fruitful discussions and Helmuth Haak for his valuable technical advice. Robert Schoetter, Nora Teichert, Angela Ruddat, and Jessica Engels are acknowledged for the ultimate icecream experience. We are also indebted to Michael Winton for information about the GFDL model. Finally, we are very grateful for the insightful comments of our three anonymous reviewers who helped to improve the manuscript.

The authors declare no conflict of interest.

\section{REFERENCES}

Abbot, D. S., and E. Tziperman, 2008: Sea ice, high-latitude convection, and equable climates. Geophys. Res. Lett., 35, L03702, doi:10.1029/2007GL032286.

Armour, K. C., I. Eisenman, E. Blanchard-Wrigglesworth, K. E. McCusker, and C. M. Bitz, 2011: The reversibility of sea ice loss in a state-of-the-art climate model. Geophys. Res. Lett., 38, L16705, doi:10.1029/2011GL048739.

Bitz, C. M., J. C. Fyfe, and G. M. Flato, 2002: Sea ice response to wind forcing from AMIP models. J. Climate, 15, 522-536, doi:10.1175/1520-0442(2002)015<0522:SIRTWF>2.0.CO;2.

Bourke, R. H., and R. P. Garrett, 1987: Sea-ice thickness distribution in the Arctic Ocean. Cold Reg. Sci. Technol., 13, 259280, doi:10.1016/0165-232X(87)90007-3.

Collins, W. J., and Coauthors, 2011: Development and evaluation of an Earth-system model-HadGEM2. Geosci. Model Dev., 4, 1051-1075, doi:10.5194/gmd-4-1051-2011.

Drijfhout, S., and Coauthors, 2015: Catalogue of abrupt shifts in Intergovernmental Panel on Climate Change climate models. Proc. Natl. Acad. Sci. USA, 112, E5777-E5786, doi:10.1073/ pnas.1511451112.

Eisenman, I., 2007: Arctic catastrophes in an idealized sea-ice model. Program of Studies: Ice (Geophysical Fluid Dynamics Program), WHOI Tech Rep. 2007-02, Woods Hole Oceanographic Institution, 133-161.

_ 2010: Geographic muting of changes in the Arctic sea ice cover. Geophys. Res. Lett., 37, L16501, doi:10.1029/ 2010GL043741.

_ 2012: Factors controlling the bifurcation structure of sea ice retreat. J. Geophys. Res., 117, D01111, doi:10.1029/2011JD016164.

— during the loss of Arctic sea ice. Proc. Natl. Acad. Sci. USA, 106, 28-32, doi:10.1073/pnas.0806887106.

— T. T. Schneider, D. S. Battisti, and C. M. Bitz, 2011: Consistent changes in the sea ice seasonal cycle in response to global warming. J. Climate, 24, 5325-5335, doi:10.1175/2011JCLI4051.1.

Fichefet, T., and M. A. Morales Maqueda, 1997: Sensitivity of a global sea ice model to the treatment of ice thermodynamics and dynamics. J. Geophys. Res., 102, 12 609-12 646, doi:10.1029/ 97JC00480.

Giorgetta, M. A., and Coauthors, 2013: Climate and carbon cycle changes from 1850 to 2100 in MPI-ESM simulations for the Coupled Model Intercomparison Project phase 5. J. Adv. Model. Earth Syst., 5, 572-597, doi:10.1002/jame.20038.

Gordon, H., and Coauthors, 2010: The CSIRO Mk3.5 climate model. CAWCR Tech. Rep. 21, CSIRO, 62 pp.

Haas, C., A. Pfaffling, S. Hendricks, L. Rabenstein, J.-L. Etienne, and I. Rigor, 2008: Reduced ice thickness in Arctic Transpolar Drift favors rapid ice retreat. Geophys. Res. Lett., 35, L17501, doi:10.1029/2008GL034457.

Hezel, P. J., T. Fichefet, and F. Massonnet, 2014: Modeled Arctic sea ice evolution through 2300 in CMIP5 extended RCPs. Cryosphere, 8, 1195-1204, doi:10.5194/tc-8-1195-2014.

Hibler, W. D., 1979: A dynamic thermodynamic sea-ice model. J. Phys. Oceanogr., 9, 815-846, doi:10.1175/1520-0485(1979)009<0815: ADTSIM $>2.0 . \mathrm{CO} ; 2$.

Holland, M. M., C. M. Bitz, and B. Tremblay, 2006: Future abrupt reductions in the summer Arctic sea ice. Geophys. Res. Lett., 33, L23503, doi:10.1029/2006GL028024.

, M. C. Serreze, and J. Stroeve, 2010: The sea ice mass budget of the Arctic and its future change as simulated by coupled climate models. Climate Dyn., 34, 185-200, doi:10.1007/ s00382-008-0493-4. 
Jahn, A., and Coauthors, 2012: Late-twentieth-century simulation of Arctic sea ice and ocean properties in the CCSM4. J. Climate, 25, 1431-1452, doi:10.1175/JCLI-D-11-00201.1.

Kwok, R., 2011: Observational assessment of Arctic Ocean sea ice motion, export, and thickness in CMIP3 climate simulations. J. Geophys. Res., 116, C00D05, doi:10.1029/ 2011JC007004.

Laxon, S. W., and Coauthors, 2013: CryoSat-2 estimates of Arctic sea ice thickness and volume. Geophys. Res. Lett., 40, 732-737, doi:10.1002/grl.50193.

Li, C., D. Notz, S. Tietsche, and J. Marotzke, 2013: The transient versus the equilibrium response of sea ice to global warming. J. Climate, 26, 5624-5636, doi:10.1175/JCLI-D-12-00492.1.

Lindsay, R. W., and J. Zhang, 2005: The thinning of Arctic sea ice, 1988-2003: Have we passed a tipping point? J. Climate, 18, 4879-4894, doi:10.1175/JCLI3587.1.

Mauritsen, T., R. G. Graversen, D. Klocke, P. L. Langen, B. Stevens, and L. Tomassini, 2013: Climate feedback efficiency and synergy. Climate Dyn., 41, 2539-2554, doi:10.1007/ s00382-013-1808-7.

McLaren, A. J., and Coauthors, 2006: Evaluation of the sea ice simulation in a new coupled atmosphere-ocean climate model (HadGEM1). J. Geophys. Res., 111, C12014, doi:10.1029/ $2005 \mathrm{JC} 003033$.

Meinshausen, M., and Coauthors, 2011: The RCP greenhouse gas concentrations and their extensions from 1765 to 2300 . Climatic Change, 109, 213-241, doi:10.1007/s10584-011-0156-z.

Notz, D., 2009: The future of ice sheets and sea ice: Between reversible retreat and unstoppable loss. Proc. Natl. Acad. Sci. USA, 106, 20 590-20 595, doi:10.1073/pnas.0902356106.

_ , F. A. Haumann, H. Haak, J. H. Jungclaus, and J. Marotzke, 2013: Arctic sea-ice evolution as modeled by Max Planck Institute for Meteorology's Earth system model. J. Adv. Model. Earth Syst., 5, 173-194, doi:10.1002/jame.20016.

O'Farrell, S. P., 1998: Investigation of the dynamic sea ice component of a coupled atmosphere-sea ice general circulation model. J. Geophys. Res., 103, 15 751-15 782, doi:10.1029/ 98JC00815.

Ogura, T., A. Abe-Ouchi, and H. Hasumi, 2004: Effects of sea ice dynamics on the Antarctic sea ice distribution in a coupled ocean atmosphere model. J. Geophys. Res., 109, C04025, doi:10.1029/2003JC002022.

Overland, J. E., and M. Wang, 2013: When will the summer Arctic be nearly sea ice free? Geophys. Res. Lett., 40, 2097-2101, doi:10.1002/grl.50316.
Pithan, F., and T. Mauritsen, 2014: Arctic amplification dominated by temperature feedbacks in contemporary climate models. Nat. Geosci., 7, 181-184, doi:10.1038/ngeo2071.

Ridley, J. K., J. A. Lowe, and H. T. Hewitt, 2012: How reversible is sea-ice loss? Cryosphere, 6, 193-198, doi:10.5194/tc-6-193-2012.

Soden, B. J., I. M. Held, R. Colman, K. M. Shell, J. T. Kiehl, and C. A. Shields, 2008: Quantifying climate feedbacks using radiative kernels. J. Climate, 21, 3504-3520, doi:10.1175/2007JCLI2110.1.

Stroeve, J., A. Barrett, M. Serreze, and A. Schweiger, 2014: Using records from submarine, aircraft and satellites to evaluate climate model simulations of Arctic sea ice thickness. Cryosphere, 8, 1839-1854, doi:10.5194/tc-8-1839-2014.

Taylor, K. E., R. J. Stouffer, and G. A. Meehl, 2012: An overview of CMIP5 and the experiment design. Bull. Amer. Meteor. Soc., 93, 485-498, doi:10.1175/BAMS-D-11-00094.1.

Thomson, J., and W. E. Rogers, 2014: Swell and sea in the emerging Arctic Ocean. Geophys. Res. Lett., 41, 3136-3140, doi:10.1002/ 2014GL059983.

Thorndike, A. S., 1992: Estimates of sea-ice thickness distribution using observations and theory. J. Geophys. Res., 97, 12 60112 605, doi:10.1029/92JC01199.

— D. A. Rothrock, G. A. Maykut, and R. Colony, 1975: The thickness distribution of sea ice. J. Geophys. Res., 80, 45014513, doi:10.1029/JC080i033p04501.

Tietsche, S., D. Notz, J. H. Jungclaus, and J. Marotzke, 2011: Recovery mechanisms of Arctic summer sea ice. Geophys. Res. Lett., 38, L02707, doi:10.1029/2010GL045698.

Uotila, P., S. O'Farrell, S. J. Marsland, and D. Bi, 2013: The sea-ice performance of the Australian climate models participating in the CMIP5. Aust. Meteor. Oceanogr. J., 63, 121-143.

Wagner, T., and I. Eisenman, 2015: How climate model complexity influences sea ice stability. J. Climate, 28, 3998-4014, doi:10.1175/ JCLI-D-14-00654.1.

Wang, M., and J. E. Overland, 2012: A sea ice free summer Arctic within 30 years: An update from CMIP5 models. Geophys. Res. Lett., 39, L18501, doi:10.1029/2012GL052868.

Watanabe, S., and Coauthors, 2011: MIROC-ESM 2010: Model description and basic results of CMIP5-20c3m experiments. Geosci. Model Dev., 4, 845-872, doi:10.5194/gmd-4-845-2011.

Winton, M., 2006: Does the Arctic sea ice have a tipping point? Geophys. Res. Lett., 33, L23504, doi:10.1029/2006GL028017.

, 2008: Sea ice-albedo feedback and nonlinear Arctic climate change. Arctic Sea Ice Decline: Observations, Projections, Mechanisms, and Implications, Geophys. Monogr., Vol. 180, Amer. Geophys. Union, 111-131, doi:10.1029/180GM09. 